\title{
Vine Response to Water Stress Induced by Polyethylene Glycol
}

\author{
J. L. VAN ZYL AND CATHERINE S. KENNEDY \\ Viticultural and Oenological Research Institute, Private Bag X5026, Stellenbosch 7600, Republic of South Africa.
}

The authors wish to express their thanks and appreciation to Mr P. A. Myburgh for his preparatory work and assistance with the glasshouse organization and Miss A. E. Theron for carrying out the statistical analyses.

Submitted for publication: November 1982

Accepted for publication: January 1983

\begin{abstract}
Polyethylene glycol (P E G) was used at different concentrations in glasshouse studies to create a range of solution osmotic potentials in an attempt to simulate the effect of water stress on vines. This was found to be a feasible technique provided that special precautions were taken to prevent $P$ E G uptake and toxicity symptoms caused by mechanical root damage. Vine response in terms of transpiration, shoot elongation rate, stomatal resistance and leaf water potential, was monitored. Significant correlations were found between solution osmotic potential and all these parameters. Shoot growth was more sensitive than stomatal opening to osmotic potential which, in turn, correlated well with transpiration rate.
\end{abstract}

There are basically three approaches to the problem of studying plant response to the availability of water viz., by means of pot experiments or lysimeters, field trials and water cultures. Maintaining a specific moisture regime in soil does, however, pose special technical problems (Slavik, 1974) as well as managerial difficulties. Inducing moisture stress in a water culture would be much easier and could be done more accurately provided an appropriate osmotic agent could be found.

Polyethylene glycol (P E G), which is a neutral polymer and is available in different molecular masses, has been used with success by several researchers (Applegate, 1960; Lagerwerff, Ogata \& Eagle, 1961; Lawlor, 1970; Frota \& Tucker, 1978; Gergely, Korcak \& Faust, 1980). Its possible uptake, mechanism of damage and toxicity were investigated by Lawlor, (1970) who found that toxic symptoms were not caused by chemical impurities but by the uptake of P E G itself. Although intact roots had a low permeability to P E G with molecular masses of 1000,4000 and 20000 , mechanical damage to the roots allowed its entry. P E G 200 had a less direct toxic effect than the higher polymers but entered the undamaged plant roots more readily and had a more gradual toxic effect. Although the mechanism of P E G damage to plants is not clear, results suggest that the pathway of transpiration is blocked by the large molecules.

Whilst interpreting data on plant response to water stress, obvious differences between a water culture and a soil medium should be borne in mind. In a water culture, water stress is created by an osmotic potential, whilst in a soil medium it is mainly caused by a matric potential (Gergely, Korcak \& Faust, 1980). Furthermore, according to Herkelrath, Miller \& Gardner, (1977), the resistance to water flow between soil and roots is high in dry soils, probably as a result of the decreased contact area between roots and soil. In a water culture this contact is ideal and should facilitate water uptake. Considering the difficulties involved in studying plant response over a full range of soil water potentials, an experiment was carried out (a) to test the applicability of the P E G technique to grapevines, and (b) to determine response curves for certain parameters in relation to solution osmotic potential. Comparisons with field data will be made at a later stage in order to evaluate the applicability of results obtained in water culture studies to field conditions.

\section{MATERIALS AND METHODS}

Two experiments were done in a glasshouse at a constant temperature of $26^{\circ} \mathrm{C}$. Colombar vines (clone $\mathrm{CO}$ 1098), propagated in a greenhouse and transplanted into a soil medium, were selected after three months, for size uniformity. These vines were subsequently transferred to a Hoagland nutrient solution which was aerated for 30 minutes in every hour in one-litre, wide-necked bottles painted black on the inside and white on the outside. Evaporation was limited by means of fairly close fitting caps around the stems of the vines. In order to allow healing of the roots which were inevitably damaged during transplantation, a period of 9 days for Experiment 1, extended to 1 month for Experiment 2, was allowed prior to the first addition of $P$ E G.

A range of solution osmotic potentials was obtained by the addition of P E G 4000 to the nutrient solution at the following concentrations:

\begin{tabular}{cc}
\hline $\begin{array}{l}\text { P E G } 4000 \\
\left(\mathrm{~g} l^{-1}\right)\end{array}$ & $\begin{array}{c}\text { Solution Osmotic Potential } \\
(\mathrm{kPa})\end{array}$ \\
\hline 0,0 (Control) & -50 \\
20,0 & -75 \\
35,0 & -100 \\
76,0 & -200 \\
100,0 & -300 \\
117,5 & -400 \\
132,5 & -500 \\
160,0 & -700 \\
190,0 & -1000 \\
214,0 & -1300 \\
226,0 & -1500
\end{tabular}

The solution osmolarity was determined with an Osmette freezing point depression osmometer.

Experiment 1 involved 26 plants, 6 of which were controls. The remaining plants were divided into 10 groups of 2 plants each and subjected to the decreasing osmotic 
potentials as shown above, at 2-day intervals. One group was maintained at each level of osmotic potential, whilst the remaining groups were exposed to the following more concentrated P E G solution, so that eventually the complete range of osmotic potentials was represented by one group of plants. Past experience indicated that gradual increasing exposure is more realistic than a sudden subjection to low potentials.

In an attempt to improve the efficiency of the method, a second experiment was done using 6 control and 6 test plants. In this case each of the test plants was gradually subjected to lower osmotic potentials every 2 days, so that the same plants could be used for all measurements. The same osmotic potential range as for the previous experiment was used. Daily water consumption was determined by measuring the quantity of distilled water needed to refill the jars to a specified level. At the end of Experiment 1, leaf areas were determined and results were expressed as millimetres water transpired per square centimetre. However, this approach did not provide for leaf growth during the course of the experiment or for the difference in growth rate between the control plants and the various treatments. In experiment 2 measurements of total leaf area were, therefore, made on certain plants throughout the duration of the experiment. These, together with the number of leaves, were used to draw a leaf growth curve. The curve was subsequently used to estimate the leaf area of all the experimental plants at various stages during the experimental period.

Stomatal resistances were determined with an automatic diffusion porometer, and leaf water potentials were measured with a pressure chamber apparatus in Experiment 1 only. A computer programme developed by Daniel \& Wood (1971), was used to calculate the correlations between solution osmotic potentials and the measured plant response parameters.

\section{RESULTS AND DISCUSSION}

The results obtained demonstrated that the plants responded to $P E \cdot G$ induced moisture stress, as was anticipated. During a test-run, lack of caution regarding the handling of the root systems during transfer from the soil and subsequent solution changes, resulted in

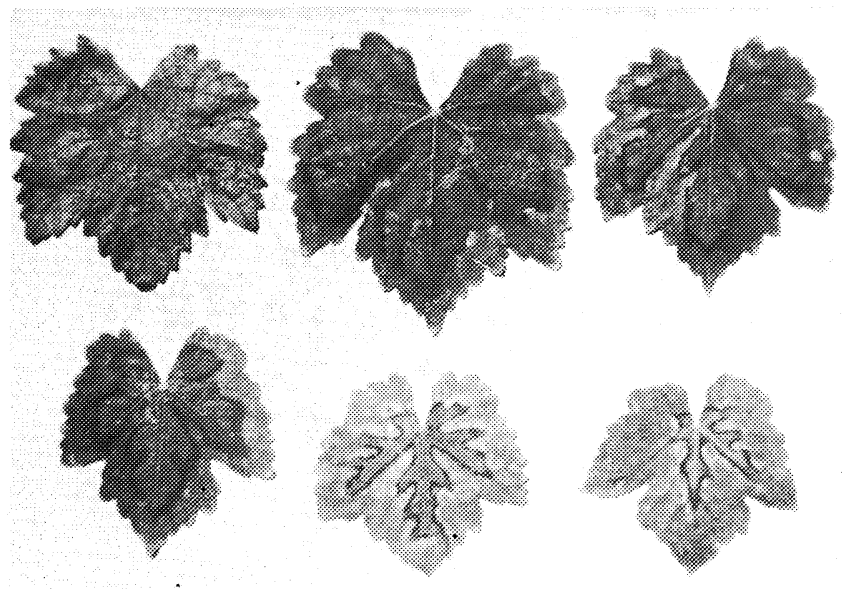

Fig. 1

Toxicity symptoms on vine leaves caused by uptake of PEG through damaged roots. Severity of necrosis increases from left to right with unaffected leaf in the upper lefthand corner. rapid and severe P E G toxicity. This was characterized by the marginal wilting and drying of leaves, which spread rapidly to the area between the veins, whereas the area immediately adjacent to the veins remained unaffected for considerably longer periods (Fig. 1).

Damage was subsequently minimized by careful handling of the roots during initial transfer to the nutrient solution, and by using a suction pump applied to the aeration system for solution removal which left the roots undisturbed throughout the course of the experiment (Fig. 2).

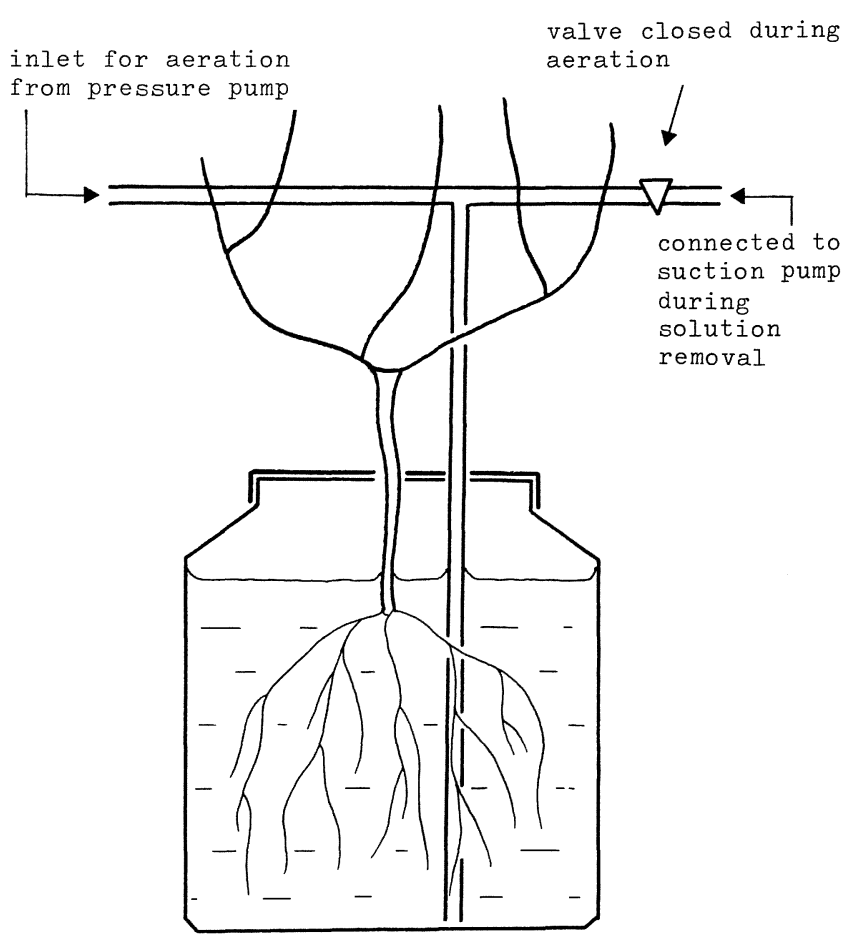

Fig. 2

Schematic presentation of system used for both aeration and solution removal.

Solution osmotic potential was found to have a highly significant $\left(R^{2}=0,68\right)$ curvilinear, negative effect on shoot growth, as illustrated in Fig. 3. The rate of shoot elongation was extremely sensitive to changes in solution osmotic potential, a finding which corresponds well with results of field experiments (Vaadia \& Kasimatis, 1961; Van der Westhuizen, 1974). At $-100 \mathrm{kPa}$ the shoot elongation rate dropped to between 40 and 50 percent of the mean control value. Very little growth occurred below $-200 \mathrm{kPa}$ and it stopped completely at $-500 \mathrm{kPa}$. Permanent wilting occurred at $-1000 \mathrm{kPa}$ (Fig. 4).

These data suggest that soil moisture potentials higher than $-100 \mathrm{kPa}$ should be maintained if maximal shoot growth is desired, as may be the case with young, nonbearing vineyards.

Similar to the effect of osmotic potential on growth rate, transpiration rate dropped sharply for initial decreases in osmotic potential, but at increasingly slower rates as further reductions were applied (Fig. 5). According to the curvilinear relationship in Fig. 5 $\left(R^{2}=0,86\right)$, vines growing at high solution osmotic potentials consumed water at a much higher rate than those at lower potentials. This confirms results from experiments with vines (Van Rooyen, Weber \& Levin, 


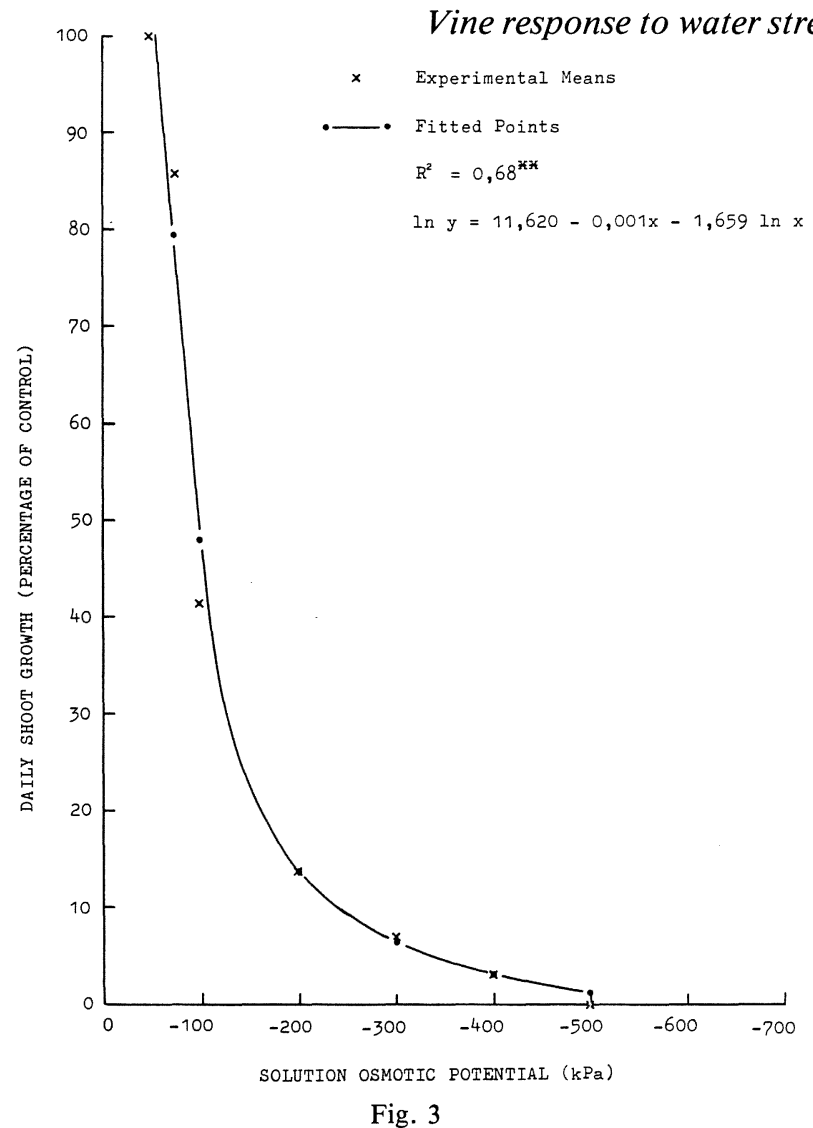

Effect of osmotic potential on the relative growth rate of vine shoots.

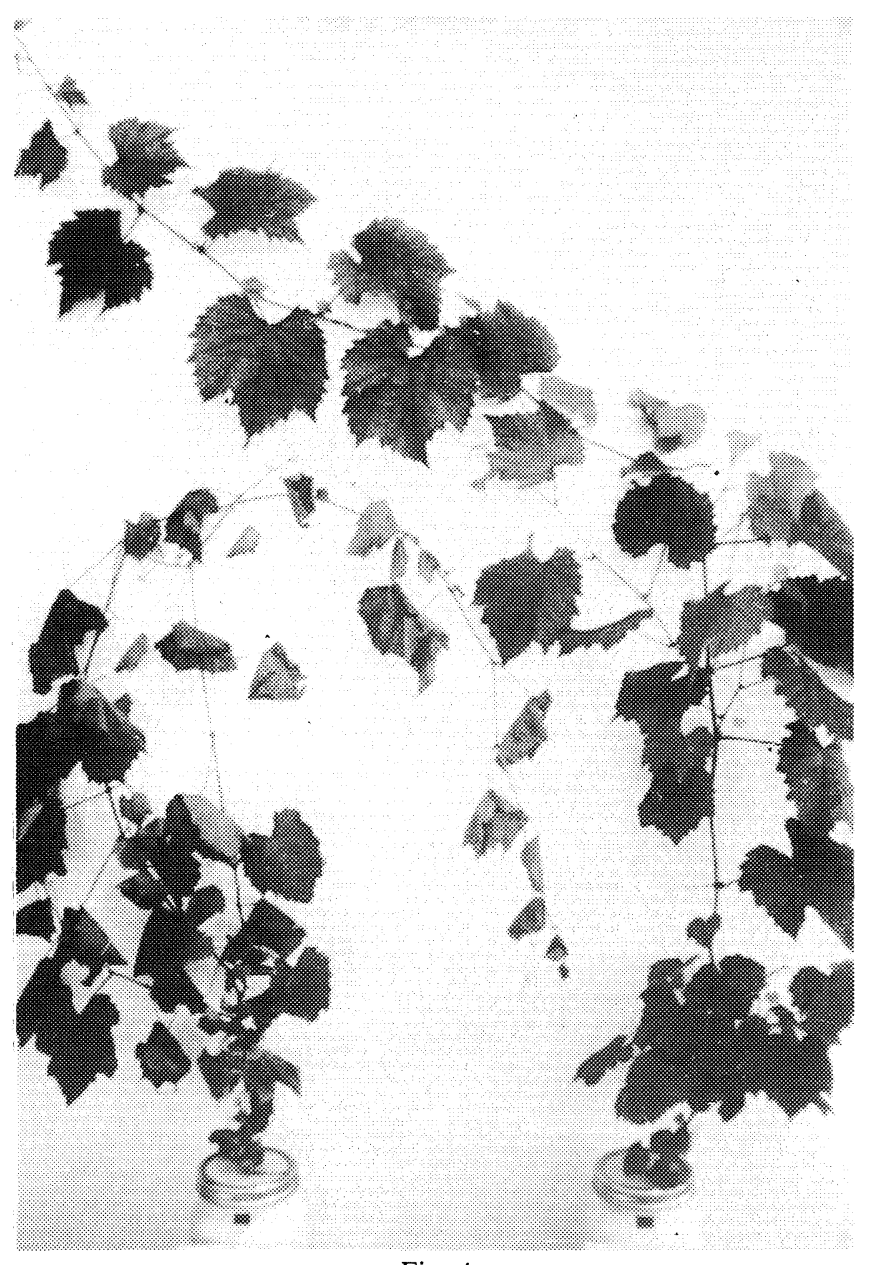

Fig. 4

Appearance of a wilted vine due to low osmotic potential (left) in comparison with the control (right).
1980) and apples (Beukes \& Weber, 1982), carried out in lysimeters and in an orchard respectively, at different soil moisture potentials. However, in contrast to the results of Gergely et al (1980), who found linear relationships between the water consumption and dry mass increase of apple seedlings versus solution osmotic potential, Figs. $3 \& 5$ indicate curvilinear relationships for vines. These response curves were obtained in both experiments.

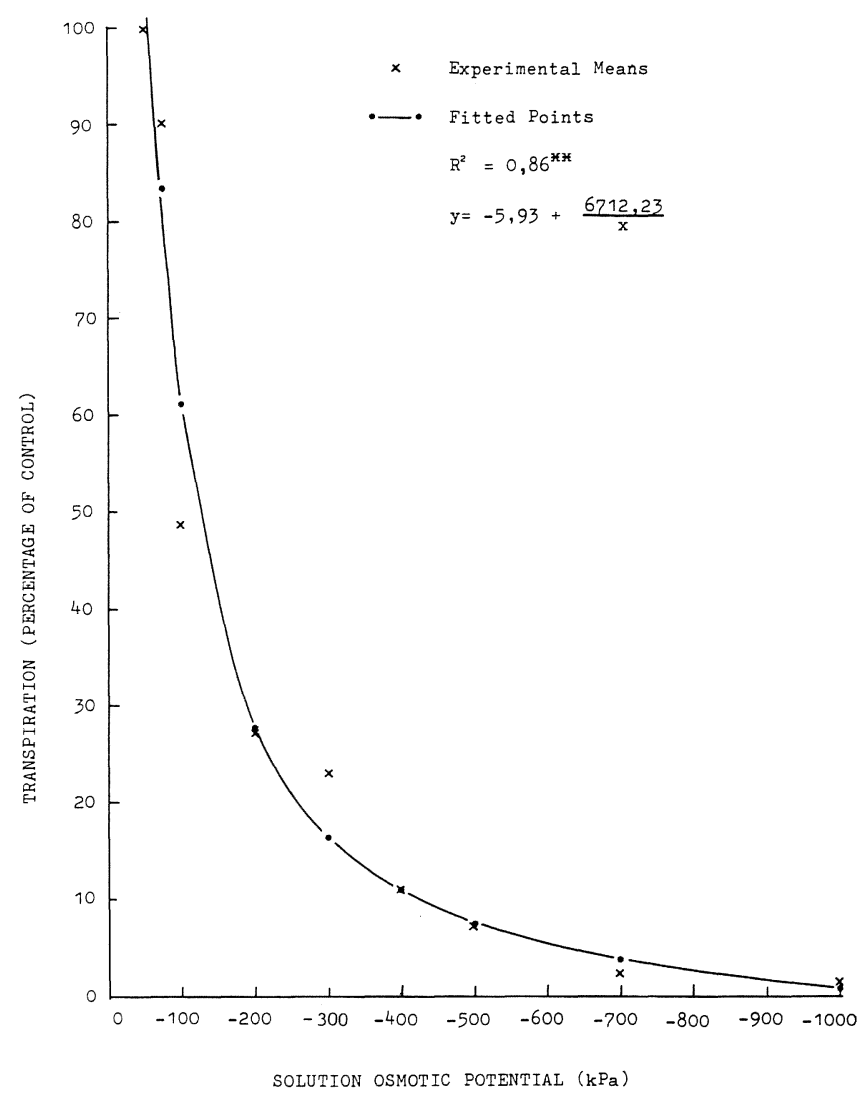

Fig. 5

Effect of solution osmotic potential on the relative transpiration rate of vines.

Statistically significant correlations between stomatal resistance and transpiration rate $\left(R^{2}=0,71\right)$ and for solution osmotic potential with stomatal conductance $\left(\mathrm{R}^{2}=0,76\right)$ which is the reciprocal of stomatal resistance, are illustrated in Figs. 6 \& 7 respectively. Transpiration rate decreased rapidly with an increase in stomatal resistance (Fig. 6) and became very low at resistance values of approximately $20 \mathrm{~s} \mathrm{~cm}^{-1}$ and higher. This corresponds fairly well with work by Liu, Pool, Wenkert \& Kriedemann (1978), who found that total closure of stomata occurred at stomatal resistances between 15 and $25 \mathrm{~S} \mathrm{~cm}^{-1}$ (stomatal conductance values $\left.=0,67-0,40 \mathrm{~mm} \mathrm{~s}^{-1}\right)$. Fig. 7 shows that stomatal conduciance values of lower than $0,4 \mathrm{~mm} \mathrm{~s}^{-1}$ were attained at a solution osmotic potential of $-400 \mathrm{kPa}$, which in most South African soils would correspond to a moisture depletion of more than 80 percent of the plant available water. The very gradual change in the slope of this graph (Fig. 7) is contrary to expectation, since Liu, Pool, Wenkert \& Kriedemann (1978) found a threshold value of leaf water potential at which stomata began to close rapidly. 


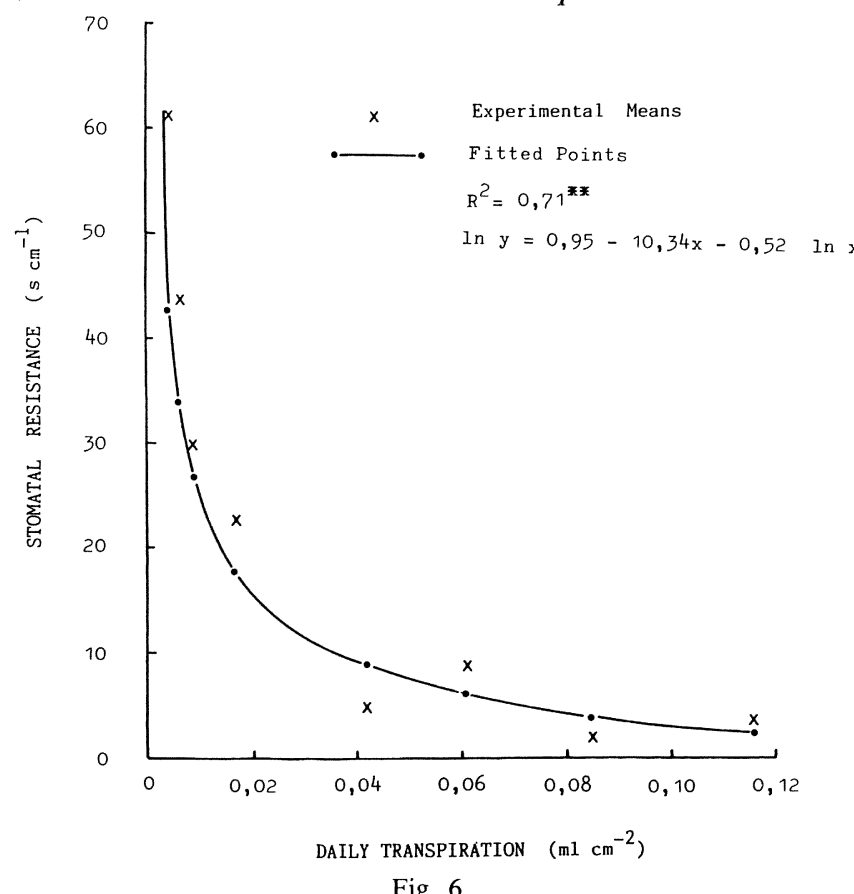

Effect of stomatal resistance on transpiration rate of vines.

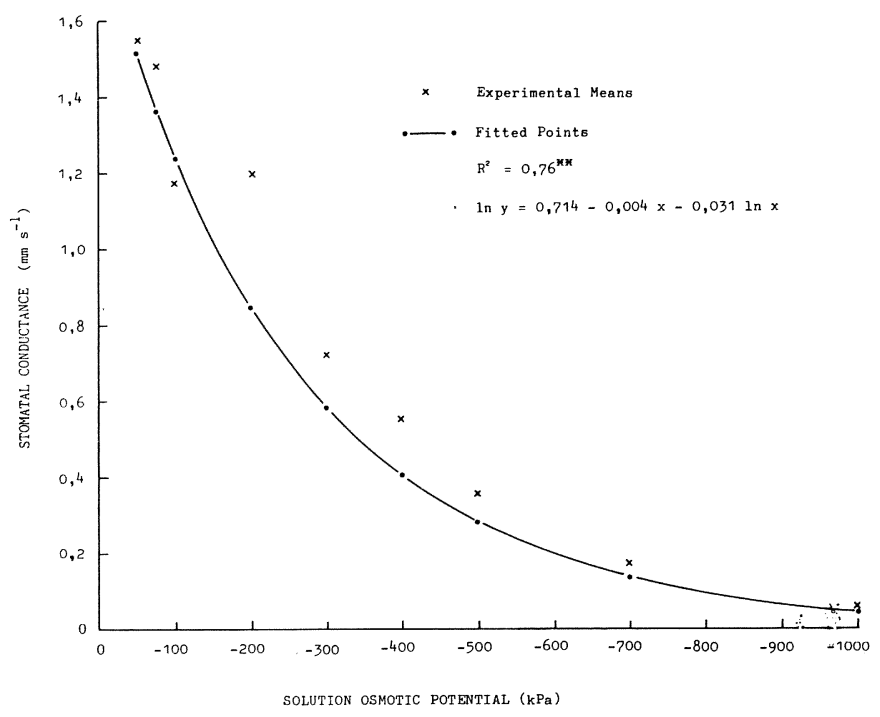

Fig. 7

Relationship between solution osmotic potential and stomatal conductance of vine leaves.

A lowering of the solution osmotic potential also decreased the leaf water potentials, as expected (Fig. 8). The leaf water potentials of the control vines were subtracted from that of each treated vine in an attempt to isolate the osmotic effect from the atmospheric demand. The absence of a $1: 1$ relationship between the corrected leaf water potential and solution osmotic potential values can probably be attributed to plant resistances to water flow and uptake. The levelling off of the curve at a leaf water potential lower than approximately $-500 \mathrm{kPa}$ (absolute value $=-906 \mathrm{kPa}$ ), is probably caused by the limited atmospheric demand in the glasshouse. A solution osmotic potential of $-400 \mathrm{kPa}$, associated with stomatal closure, indicated a leaf water potential of approximately $-906 \mathrm{kPa}$, compared to values of $-1300 \mathrm{kPa}$ found by Liu, Pool, Wenkert \& Kriedemann (1978) with potted vines under normal atmospheric conditions.

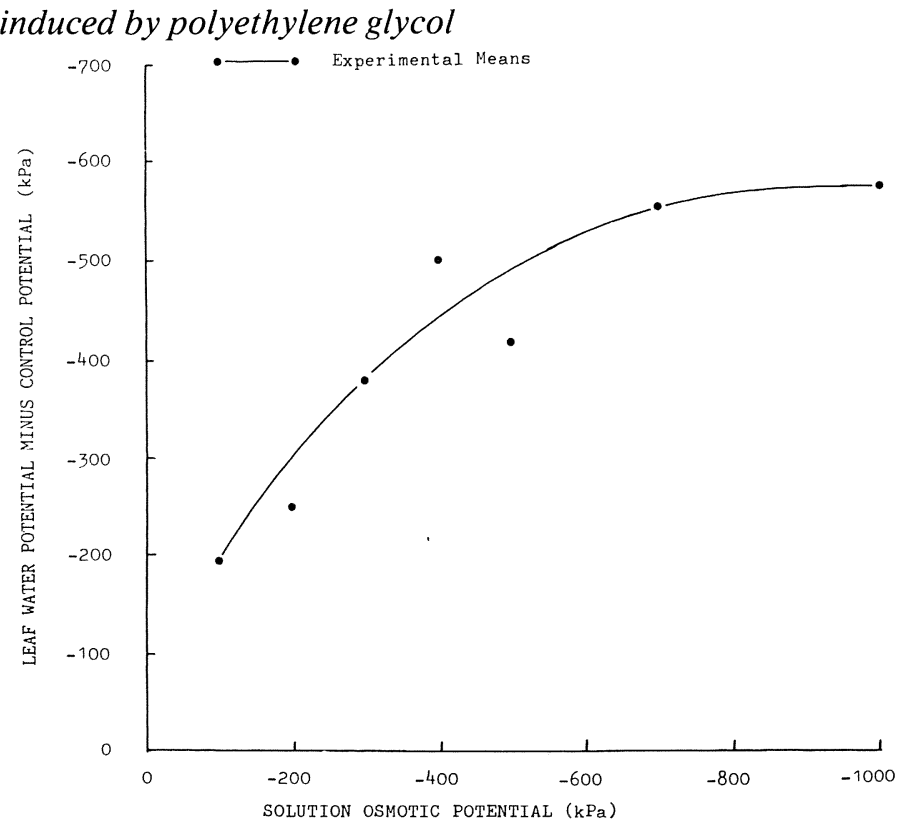

Fig. 8

Effect of solution osmotic potential on leaf water potential of vines.

It is clear from the foregoing discussion that stomatal opening can be an indicator of vine water status. However, environmental factors such as the diurnal pattern (Smart, 1974), leaf temperature (Millar, 1972), photosynthetically active radiation and previous night minimum temperatures (Liu, Wenkert, Allen \& Lemon, 1978) may also affect the stomatal opening.

\section{SUMMARY AND CONCLUSIONS}

P E G 4000 was found to be a suitable osmotic agent for inducing water stress in vines growing in a water culture. Mechanical root damage, however, led to P E G uptake resulting in necrosis of the leaves and the dying of the plant. A sufficient healing period of at least two weeks for roots after transplanting is, therefore, needed and special attention should be given to the handling of the plants during solution renewal.

$\mathrm{P}$ E G concentrations representing a range of osmotic potentials from $-50 \mathrm{kPa}$ to $-1500 \mathrm{kPa}$ made it feasible to study, within a short period of time, the response of several plant parameters to moisture stress. In this study both transpiration and shoot growth correlated highly significantly with solution osmotic potential. Shoot growth was already reduced by more than 50 percent at an osmotic potential as high as $-100 \mathrm{kPa}$. Stomatal resistance was less sensitive to moisture stress than shoot growth, but no threshold value of solution osmotic potential was found at which stomata started to close rapidly. A highly significant relationship between transpiration and stomatal resistance was shown. It would appear therefore, that stomatal opening can provide a useful indicator of vine water status, but it must be borne in mind that environmental factors may also affect stomatal movement.

\section{LITERATURE CITED}

APPlEGATE, H. G., 1960. Freezing point depressions of Hoagland's "Carbowax" systems. Nature 186, 232-233.

BEUKES, D. J. \& WEBER, H. W., 1982. The effects of irrigation at different soil water levels on the water use characteristics of apple trees. J. Hort. Sci. 57, in press. 
DANIEL, C. \& WOOD, F. S., 1971. Fitting equations to data. WileyInterscience, New York and London.

FROTA, J. N. E. \& TUCKER, T. C., 1978. Salt and water stress influences nitrogen metabolism in Red Kidney beans. Soil. Sci. Soc. Am. J. 42, 743-746.

GERGELY, I., KORCAK, R. F. \& FAUST, M., 1980. Polyethylene glycol induced water stress effects on apple seedlings. I. Methodology, water consumption and dry matter production. J. Amer. Soc. Hort. Sci. 105, 854-857.

HERKELRATH, W. N., MILlER, E. E. \& GARDNER, W. R., 1977. Water uptake by plants: I. Divided root experiments. Soil Sci. Soc. Am. J. 41, 1033-1038.

LAGERWERFF, J. C., OGATA, G. \& EAGLE, H. E., 1961. Control of osmotic pressure of culture solutions with polyethylene glycol. Science 133, 1486-1487.

LAWLOR, D. W., 1970. Absorption of polyethylene glycols by plants and their effects on plant growth. New Phytol. 69,501-513.

LIU, W. T., POOL, R., WENKERT, W. \& KRIEDEMANN, P. E., 1978. Changes in photosynthesis, stomatal resistance and abscisic acid of Vitis labruscana through drought and irrigation cycles. Am. J. Enol. Vitic. 29, 239-246.
LIU, W. T., WENKERT, W., ALLEN, L. H. \& LEMON, E. R., 1978. Soil-plant water relations in a New York vineyard: Resistances to water movement. J. Amer. Soc. Hort. Sci. 103, 226-230.

MILlAR, A. A., 1972. Thermal regime of grapevines. Am. J. Enol. Vitic. 23, 173-176.

SLAVIK, B., 1974. Methods for studying plant water relations. Ecological studies, Vol. 9, Springer-Verlag, Berlin and New York.

SMART, R. E., 1974. Aspects of water relations of the grapevine (Vitis vinifera). Am. J. Enol. Vitic. 25, 84-91.

VAADIA, Y.\& KASIMATIS, A. N., 1961. Vineyard irrigation trials. Am. J. Enol. Vitic. 12, 88-98.

VAN DER WESTHUIZEN, J. H., 1974. Waterhuishouding en besproeiingsbehoefte van wyndruiwe: Maatstawwe vir die bepaling van die besproeiingsbehoefte van wyndruiwe. Projek (S)WI $47 / 2$, Finale Verslag, N I W W, Privaatsak X5026, Stellenbosch.

VAN ROOYEN, F. C., WEBER, H. W. \& LEVIN, I., 1980. The response of grapes to a manipulation of the soil-plant-atmosphere continuum. II. Plant-water relationships. Agrochemophysica 12, 69-74. 